\title{
Oxonol VI as an optical indicator for membrane potentials in lipid vesicles
}

\author{
H.-J. Apell and B. Bersch \\ Department of Biology, University of Konstanz, Konstanz (F.R.G.)
}

(Received 29 April 1987)

Key words: Oxonol dye; ATPase, $\left(\mathrm{Na}^{+}+\mathrm{K}^{+}\right)$-; Lipid vesicle; Membrane potential; Fluorescence

Experiments with large unilamellar dioleoylphosphatidylcholine vesicles were carried out in order to study the effect of membrane potential on the fluorescence of Oxonol VI. A partition equilibrium of dye between membrane and water was found to exist with a partition coefficient $\gamma \equiv c_{\text {lipid }} / c_{\text {water }}$ of about 19000 (at zero voltage). In the presence of an inside-positive membrane potential, the negatively charged dye accumulates in the intravesicular aqueous space according to a Nernst equilibrium. This leads to an increased adsorption of dye to the inner lipid monolayer and to a concomitant increase of fluorescence. The fluorescence change can be calibrated as a function of transmembrane voltage by generating a potassium diffusion potential in the presence of valinomycin. The intrinsic fluorescence of the membrane-bound dye is not affected by voltage; the whole influence of voltage on the fluorescence results from voltage-dependent partitioning of the dye between water and membrane. The voltage dependence of the apparent partition coefficient can be quantitatively described by a three-capacitor model in which the dye is assumed to bind to adsorption planes located on the hydrocarbon side of the membrane/solution interface. Oxonol VI was found to be suitable for detecting changes of membrane potential associated with the activity of the $\left(\mathrm{Na}^{+}+\mathrm{K}^{+}\right)$-ATPase in reconstituted vesicles. When ATP is added to the external medium, pump molecules with the ATP-binding side facing outward become activated; this results in a translocation of net positive charge towards the vesicle interior. Under this condition, fluorescence changes corresponding to (inside-positive) potentials of up to $150-200 \mathrm{mV}$ are observed. After the build-up of the membrane potential, a quasi-stationary state is reached in which the pump current is compensated by a back-flow of charge through passive conductance pathways.

\section{Introduction}

Voltage-sensitive dyes are widely used for measuring membrane potentials of cells, cell organelles and membrane vesicles [1-4]. Experiments with intact cells usually require the detection of insidenegative potentials, and most voltage-sensitive dyes have been selected for this purpose. Oxonols (Fig. 1) belong to the few dyes which have been suc-

Correspondence: H.J. Apell, Department of Biology, University of Konstanz, D-7750 Konstanz, F.R.G. cessfully used in the measurement of inside-positive potentials [5-7]. Oxonols V, VI and VII have a $\mathrm{p} K$ near 4.2 and are anionic at physiological $\mathrm{pH}$ values [5,7]. They have been applied in studies with submitochondrial particles [8-11], chloroplasts $[12,13]$, bacterial chromaffin granula [16], plasma-membrane vesicles $[17,18]$ and (proteo) liposomes [7,19-22].

Oxonols are known to bind strongly to membrane vesicles; upon binding, both the absorption and the emission spectrum are shifted towards longer wavelengths $[5,7]$. Generation of an insidepositive membrane potential increases this red-

Konstanzer Online-Publikations-System (KOPS)

URL: http://www.ub.uni-konstanz.de/kops/volltexte/2007/3960/

URN: http://nbn-resolving.de/urn:nbn:de:bsz:352-opus-39601 


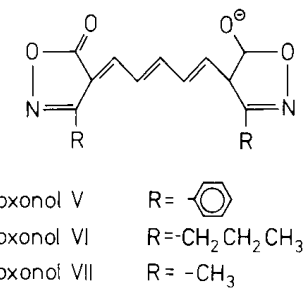

Fig. 1. Structure of oxonols.

shift $[14,15]$. Furthermore, evidence has been obtained that oxonol anions easily permeate through lipid bilayers $[6,7,14,23]$. Based on these observations, it has been proposed that in the presence of an inside-positive potential, vesicles accumulate the anionic dye in the intravesicular aqueous space, which leads to enhanced binding of the dye to the membrane and to a concomitant spectral change $[14,15,19]$.

In the follow, we describe a quantitative test of the proposed mechanism of voltage sensitivity of oxonol dyes, using large unilamellar dioleoylphosphatidylcholine vesicles prepared by detergent dialysis. We show that the experimental results indeed can be explained by the assumption of a voltage-dependent dye distribution between intraand extravesicular aqueous space, provided that the theoretical model is suitably modified as to account for a direct field effect on the membrane--water partition coefficient of the dye.

The main incentive for this study was the possibility of using oxonol dyes as voltage indicators in studies with reconstituted $\left(\mathrm{Na}^{+}+\mathrm{K}^{+}\right)$-ATPase vesicles [24]. Activation of $\mathrm{Na}^{+}, \mathrm{K}^{+}$-pump molecules inserted into the vesicle membrane by addition of ATP to the medium generates an insidepositive membrane potential. The analysis of the electrogenic effect of the pump requires a calibration of the observed spectral changes as a function of transmembrane voltage. Calibration experiments will be described below in which a Nernst potential for potassium was created in the presence of valinomycin. Furthermore, preliminary results from experiments with reconstituted $\left(\mathrm{Na}^{+}+\right.$ $\mathrm{K}^{+}$)-ATPase vesicles will be presented.

\section{Materials and Methods}

Materials

Dioleoylphosphatidylcholine was obtained from Avanti Polar Lipids, Birmingham, AL, U.S.A.; Oxonol VI (bis(3-propyl-5-oxoisooxazol-4-yl)pentamethin oxonol) was from Molecular Probes, Junction City, OR, U.S.A., ATP (Sonderqualität) and valinomycin from Boehringer-Mannheim, Vanadate from Ventron, Karlsruhe. The phospholipid contents were determined by the Phospholipid B test from Wako Pure Chemical Industries, Ltd., Osaka, Japan. All other reagents were obtained from Merck (analytical grade). Dialysis tube was purchased from Serva, Heidelberg.

\section{Vesicle preparations}

Lipid vesicles were prepared from synthetic dioleoylphosphatidylcholine as described previously by a dialysis method producing homogeneous, unilamellar vesicles with an average outer diameter of $72 \mathrm{~nm}$ [24]. $\left(\mathrm{Na}^{+}+\mathrm{K}^{+}\right)$-ATPase was prepared from outer medulla of rabbit kidneys using procedure $\mathrm{C}$ of Jørgensen [25], as described previously $[24,26]$. The specific activity was in the range of $1700-2100 \mu \mathrm{mol} \mathrm{P}_{\mathrm{i}}$ per $\mathrm{h}$ per $\mathrm{mg}$ at $37^{\circ} \mathrm{C}$. Reconstituted vesicles containing $\left(\mathrm{Na}^{+}+\right.$ $\mathrm{K}^{+}$)-ATPase were prepared by cholate removement in 'buffer $\mathrm{H}$ ' containing $30 \mathrm{mM}$ imidazole, 1 $\mathrm{mM}$ L-cysteine, $1 \mathrm{mM}$ EDTA, $5 \mathrm{mM} \mathrm{MgSO}_{4}$ and various amounts of $\mathrm{Na}_{2} \mathrm{SO}_{4}$ and $\mathrm{K}_{2} \mathrm{SO}_{4}$. The average outer diameter of protein-containing vesicles has been previously determined to be about $96 \mathrm{~nm}$ [24].

\section{Fluorescence measurements}

Fluorescence experiments were carried out in a Perkin Elmer 650-40 fluorescence spektrophotometer. The thermostatically controlled cuvette holder was equipped with a magnetic stirrer. If not otherwise indicated, the excitation wavelength was set to $580 \mathrm{~nm}$ (slit width $20 \mathrm{~nm}$ ) and the emission wavelength to $660 \mathrm{~nm}$ (slit width $5 \mathrm{~nm}$ ). The Oxonol VI stock solution contained $3.16 \mathrm{mM}$ dye in ethanol. From this stock solution dilutions were prepared by mixing with ethanol/water $(1 / 5$, $v / v)$. Concentrations were chosen such that addition of $5 \mu 1$ dye solution to the cuvette resulted in the desired final concentration $(10-500 \mathrm{nM})$. 
The dilute dye solutions were prepared daily. All fluorescence data were normalized with respect to a fluorescence standard.

The cuvette was filled with $1 \mathrm{ml}$ buffer and equilibrated in the cuvette holder to the designed temperature. After the background fluorescence was measured, $5 \mu 1$ of an Oxonol VI solution was added. After the fluorescence signal was constant, an aliquot of the vesicle suspension was added. Fluorescence changes, $\Delta F$, caused by additions of reagents were determined as relative signal changes with respect to the fluorescence level, $F_{0}$, prior to the addition; they were corrected for the small dilution effect which was determined separately by adding a known amount of buffer solution. At the beginning and at the end of each experiment the temperature in the cuvette was controlled and the fluorescence signal of the standard was determined. If not otherwise indicated, the experiments were carried out at $20^{\circ} \mathrm{C}$.

\section{Results}

Spectral properties as a function of dye and lipid concentration

The absorption and emission spectra of Oxonol

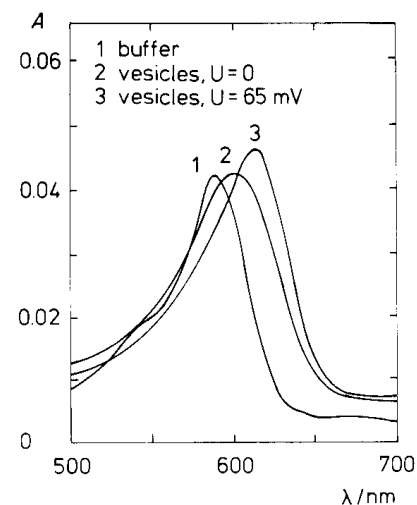

Fig. 2. Optical absorbance $(A)$ of a solution of $0.52 \mu \mathrm{M}$ Oxonol VI in buffer $\mathrm{H}$ as a function of wavelength $\lambda$. Curve 1: dye in free buffer solution; curve 2 ; after addition of vesicles (50 $\mu \mathrm{g} \mathrm{lipid} / \mathrm{ml}$ ); curve $3:$ as 2 , in the presence of an inside-positive membrane potential of $U=65 \mathrm{mV}$. The membrane potential was created by a potassium gradient $\left[\mathrm{K}^{+}\right]_{\mathrm{i}}=10$ $\mathrm{mM},\left[\mathrm{K}^{+}\right]_{0}=140 \mathrm{mM}$ and $10 \mathrm{nM}$ valinomycin to the medium; the value of $U$ was calculated from Eqn. 6 .
VI in free aqueous solution and in the presence of dioleoylphosphatidylcholine vesicles are represented in Figs. 2 and 3. It is seen that both the absorption and the emission peak are red-shifted when the dye interacts with the lipid and that a further red-shift occurs when an inside-positive membrane potential is generated. Furthermore, the fluorescence intensity increases (at an excitation wavelength of $580 \mathrm{~nm}$ ) upon binding of the dye to the vesicles. As shown by Fig. 4 , the peak wavelength $\lambda_{\max }$, as well as the peak intensity $F_{\max }$ approach limiting values when the lipid concentration is increased at a constant (overall) concentration of Oxonol VI. This indicates that at the highest lipid concentrations used in the experiment $(170 \mu \mathrm{g} / \mathrm{ml})$ virtually all dye is bound to the vesicles.

Determination of the partition coefficient, $\gamma$, at zero voltage

The membrane-water partition coefficient, $\gamma$, of the dye is defined by

$\gamma=\frac{n_{1} / V_{1}}{n_{\mathrm{w}} / V_{\mathrm{w}}}$

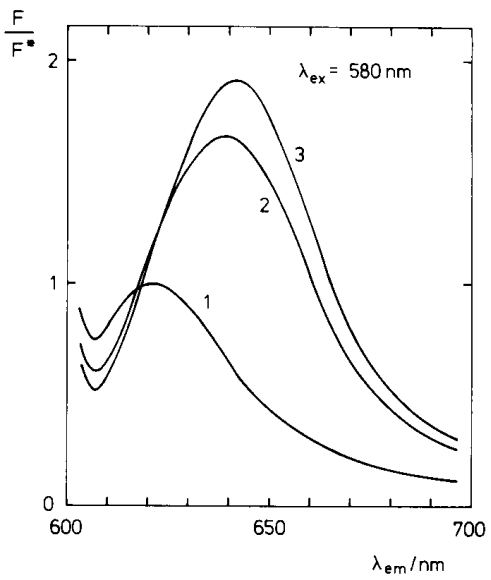

Fig. 3. Fluorescence intensity, $F$ (normalized to the peak value, $F^{*}$, of curve 1 ), as a function of emission wavelength, $\lambda_{\text {en }}$ The excitation wavelength was $580 \mathrm{~nm}$. Slid widths: $20 \mathrm{~nm}$ (excitation) and $5 \mathrm{~nm}$ (emission). Curve 1: $0.13 \mu \mathrm{M}$ oxonol VI in buffer $\mathrm{H}$; curve 2 : after addition of vesicles $(45 \mu \mathrm{g} \mathrm{lipid} / \mathrm{ml})$; curve 3: as 2, in the presence of an inside-positive membrane potential $U$ of $36 \mathrm{mV}$ created by adding $\mathrm{K}^{+}$and $10 \mathrm{nM}$ valinomycin to the medium, the value of $U$ was calculated from Eqn. 6. 


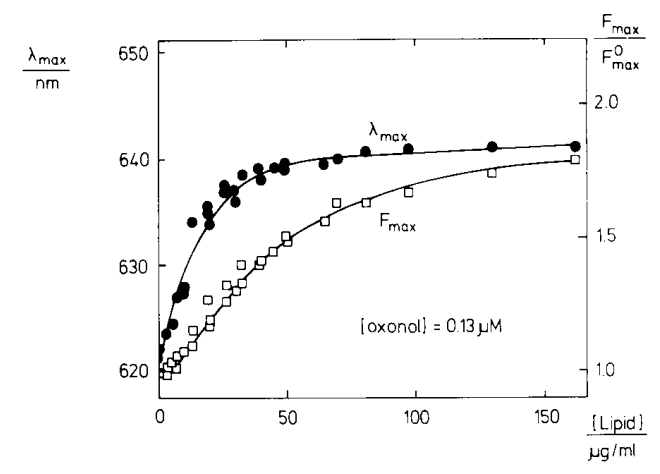

Fig. 4. Wavelength $\lambda_{\max }$ and fluorescence intensity $F_{\max }$ at the emission peak (excitation wavelength $580 \mathrm{~nm}$ ) as a function of lipid concentration, at a constant (overall) dye concentration of $0.13 \mu \mathrm{M}$ in buffer $\mathrm{H} . F_{\max }$ is referred to the peak intensity $F_{\max }^{0}$ at zero lipid concentration. The curves have been drawn to guide the eye.

where $n_{1}$ and $n_{\mathrm{w}}$ are the amounts of dye (in mol) in the lipid phase and in the water phase and $V_{1}$ and $V_{\mathrm{w}}$ are the volumes of the lipid and water phases. If $f_{\mathrm{w}}$ and $f_{1}$ are the contributions of one mole of dye in the water and in the lipid to the observed fluorescence, the total fluorescence intensity, $F$, can be represented by

$F=n_{\mathrm{w}} f_{\mathrm{w}}+n_{1} f_{1}$

In the following, $F$ is referred to the fluorescence intensity measured with a fluorescence standard and is expressed in dimensionless units, so that $f_{\mathrm{w}}$ and $f_{1}$ have the dimension $\mathrm{mol}^{-1}$. Eqns. 1 and 2 together give

$F=n \frac{f_{\mathrm{w}} V_{\mathrm{w}}+\gamma f_{1} V_{1}}{V_{\mathrm{w}}+\gamma V_{1}}$

where $n=n_{\mathrm{w}}+n_{1}$ is the total amount of dye in the fluorescence cuvette. Eqn. 3 predicts that the ratio $F / n$ should be independent of oxonol concentration. This expectation is borne out by the experiments. As seen from Fig. 5, values of $F / n$ for three different oxonol concentrations $(125,250$ and $500 \mathrm{nM}$ ) fall nearly on the same line when $F / n$ is plotted as a function of lipid concentration. At all oxonol concentrations, the optical absorbance of the solution is so low that self-ab-

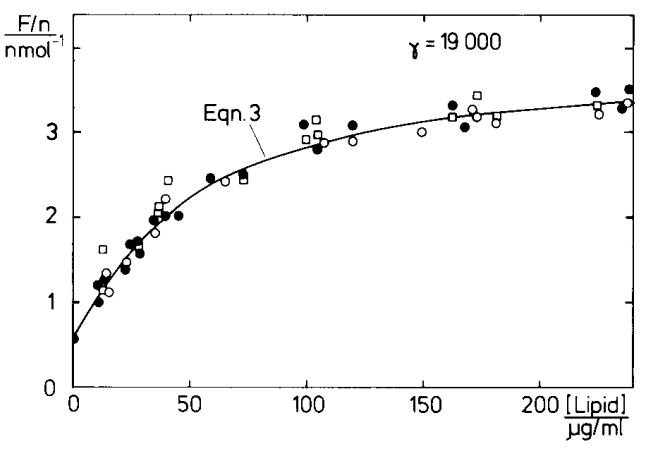

Fig. 5. Fluorescence intensity $F$, divided by the total amount, $n$, of Oxonol VI in the fluorescence cuvette. $F$ is referred to a fluorescence standard and is given in dimensionless units; $n$ is expressed in nmol. The dependence of $F / n$ on lipid concentration was measured at different concentrations of Oxonol VI: $125 \mathrm{nM}$; O, $250 \mathrm{nM}$; $\square, 500 \mathrm{nM}$. At all Oxonol concentrations the optical absorbance was so low that self-absorption, at a pathlength of $1 \mathrm{~cm}$, was negligible. The curve represents a fit of Eqn. 3 using the following parameter values: $f_{\mathrm{w}}=0.55 \mathrm{nmol}^{-1}$,

$$
f_{1}=4.1 \mathrm{nmol}^{-1}, \gamma=19000 \text {. }
$$

sorption, at a pathlength of $1 \mathrm{~cm}$, is negligible. Eqn. 3 can be fitted to the experimentally observed dependence of $F / n$ on lipid concentration, using the known values of $V_{\mathrm{w}}$ and $V_{1}\left(V_{\mathrm{w}}\right.$ is nearly to the total volume, $V=1 \mathrm{ml}$, of the vesicle suspension in the fluorescence cell, and $V_{1}$ is obtained from the concentration and the density, $\rho \approx 9 \mathrm{mg} / \mathrm{cm}^{3}$, of the lipid). The theoretical curve in Fig. 5 adequately describes the experimental results; from the fit the values of the fluorescence parameters, $f_{\mathrm{w}}$ and $f_{1}$, and of the partition coefficiency, $\gamma$, can be determined to be $f_{\mathrm{w}}=0.55$ $\mathrm{nmol}^{-1}, f_{1}=4.1 \mathrm{nmol}^{-1}$ and $\gamma=19000$.

Membrane potentials generated by $\mathrm{K}^{+}$-concentration gradients

Membrane potentials may be generated by establishing a transmembrane $\mathrm{K}^{+}$-concentration difference in the presence of valinomycin. At the beginning of the experiment, the $\mathrm{K}^{+}$concentration is the same in the intra- and extravesicular aqueous space, and the membrane is made selectively permeable by the addition of valinomycin. When the extravesicular $\mathrm{K}^{+}$concentration is increased, a Nernst potential for $\mathrm{K}^{+}$,

$U=\psi^{\prime}-\psi^{\prime \prime}=\frac{R T}{F} \ln \frac{c^{\prime \prime}}{c^{\prime}}$ 
is created. $\psi^{\prime}$ and $\psi^{\prime \prime}$ are the intra- and extravesicular potentials, respectively, and $c^{\prime}$ and $c^{\prime \prime}$ are the corresponding $\mathrm{K}^{+}$concentrations; $R$ is the gas constant, $T$ the absolute temperature and $F$ the Faraday constant. For the generation of the voltage $U$, an electric charge, $Q$, has to move across the membrane in order to charge up the membrane capacitance, $A C_{\mathrm{m}}$ ( $A$ is the total membrane area and $C_{\mathrm{m}} \equiv 1 \mu \mathrm{F} / \mathrm{cm}^{2}$ is the specific membrane capacitance):

$Q=A C_{\mathrm{m}} U$

The inward movement of $\mathrm{K}^{+}$associated with the establishment of the Nernst potential increases the intravesicular $\mathrm{K}^{+}$concentration from an initial value $c_{0}^{\prime}$ to a final value $c^{\prime}$. If the membrane-permeable anionic dye is added to the medium, an additional transmembrane charge transport occurs, as the dye equilibrated between extra- and intravesicular aqueous space. This contribution of the dye to the membrane potential can, in general, not be neglected, although the effect may be small at low dye concentrations (see below). Under the condition that the volume of the intravesicular aqueous space is small compared to the total volume, the extravesicular $\mathrm{K}^{+}$concentration, $c^{\prime \prime}$, remains virtually constant during the build-up of the membrane potential. The intravesicular $\mathrm{K}^{+}$ concentration changes, however, from the initial value, $c_{0}^{\prime}$, to a final value, $c^{\prime}$. As shown in Appendix $\mathrm{A}, c^{\prime}$ and $c_{0}^{\prime}$ are related by

$c^{\prime}=c_{0}^{\prime}+C^{*} \ln \frac{c_{0}^{\prime \prime}}{c^{\prime}}+\frac{(1+\sigma) c_{\mathrm{D}} c_{0}^{\prime \prime}}{(1+a \sigma) c^{\prime}+a(1+\sigma) c_{0}^{\prime \prime}}$

$C^{*} \equiv \frac{R T}{F^{2}} \cdot \frac{A C_{\mathrm{m}}}{V^{\prime}}$

$\sigma \equiv \gamma V_{1} / 2 V^{\prime} ; a \equiv V^{\prime} / V^{\prime \prime}$

$C^{*}$ has the meaning of the concentration of univalent ions, referred to intravesicular volume, $V^{\prime}$, which are required to charge up the membrane capacitance to a voltage of $R T / F \approx 25 \mathrm{mV}$. For a spherical vesicle of internal radius $r=32 \mathrm{~nm}$, this concentration is given by $C^{*}=3 R T C_{\mathrm{m}} / F^{2} r \approx 250$ $\mu \mathrm{M}$. The ratio, $a$, of intra- and extravesicular aqueous volume was always small; at the highest experimental lipid concentrations (about 200 $\mu \mathrm{g} / \mathrm{ml}), a$ is of the order of $10^{-3}$. For a spherical vesicle, the quantity $\sigma$ may be estimated to be $\sigma=3 \gamma d / 2 r$, where $d$ is the membrane thickness. With the experimentally determined partition coefficient, $\gamma \approx 19000, \sigma$ becomes about 2000 . Eqn 6, which refers to an equilibrium state, is valid irrespective of the order of addition of valinomycin, $\mathrm{K}^{+}$and the dye. If $c^{\prime}$ is numerically evaluated from Eqn. 6, the membrane potential $U$ can be calculated from Eqn. 4 (with $c^{\prime \prime}=c_{0}^{\prime \prime}$ ).

Eqn. 6 limits the absolute magnitude of membrane potentials which can be generated by the $\mathrm{K}^{+}$-gradient method. If the initial intravesicular potassium concentration is zero $\left(c_{0}^{\prime}=0\right)$, the relation $C^{*} \ln \left(c_{0}^{\prime \prime} / c^{\prime}\right)=c^{\prime}$ holds for small dye concentrations $\left(c_{\mathrm{D}} \approx 0\right)$. This yields, with $C^{*}=250$ $\mu \mathrm{M}$ and $c_{0}^{\prime \prime}=140 \mathrm{mM}$, a final intravesicular $\mathrm{K}^{+}$ concentration of $c^{\prime} \approx 0.5 \mathrm{mM}$ and, according to Eqn. 4, a membrane potential $U \approx 140 \mathrm{mM}$. This value of $U$ represents a practical upper limit of the voltage range in which fluorescence signals can be calibrated by the Nernst-potential method. In Fig. 6 the membrane potential, $U$, predicted from Eqns. 4 and 6 is plotted as a function of $c_{0}^{\prime \prime} / c_{0}^{\prime}$ for a fixed value $c_{0}^{\prime \prime}=140 \mathrm{mM}$ and a total dye concentration of either $c_{\mathrm{D}}=0$ or $c_{\mathrm{D}}=1 \mu \mathrm{M}$. The

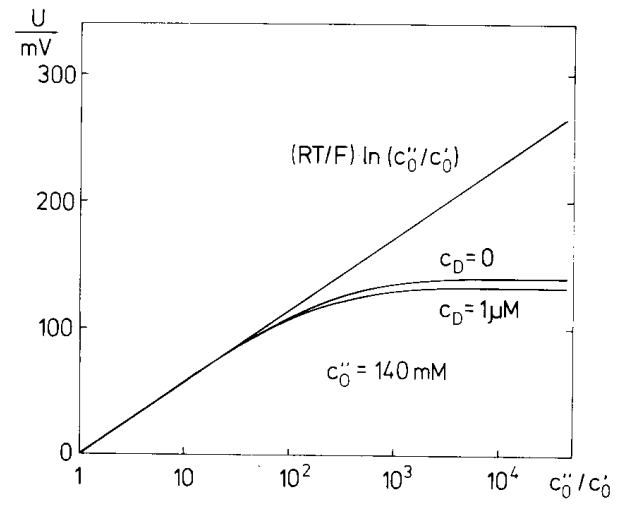

Fig. 6. Membrane potential, $U$, in the presence of a $\mathrm{K}^{+}$ concentration difference. $c_{0}^{\prime}$ and $c_{0}^{\prime \prime}$ are the initial intra- and extravesicular $\mathrm{K}^{+}$concentrations, respectively, prior to the build-up of the membrane potential. The uppermost curve has been calculated from the Nernst equation assuming a constant intravesicular $\mathrm{K}^{+}$concentration. The lower curves have been obtained from Eqns. 4 and 6 with $c^{\prime \prime}=c_{0}^{\prime \prime}=140 \mathrm{mM}, a=10^{-4}$ $\sigma=1980$, and $C^{*}=250 \mu \mathrm{M}$. 
difference of the curves for $c_{D}=0$ and $c_{D}=1 \mu \mathrm{M}$ represents the influence of the third term on the right side of Eqn. 6. It is seen that at concentrations as large as $c_{\mathrm{D}}=1 \mu \mathrm{M}$ the effect of dye translocation on membrane potential is small. In most experiments, however, $c_{\mathrm{D}}$ was much lower. This means that the term proportional to $c_{\mathrm{D}}$ in Eqn. 6 can be neglected under the conditions of our experiments.

\section{Voltage-induced fluorescence changes}

When an inside-positive membrane potential is generated by a $\mathrm{K}^{+}$-concentration difference in the presence of valinomycin, the fluorescence intensity, $F$, increases (Fig. 7). The experimentally observed dependence of fluorescence intensity onlipid concentration was compared with the predict-

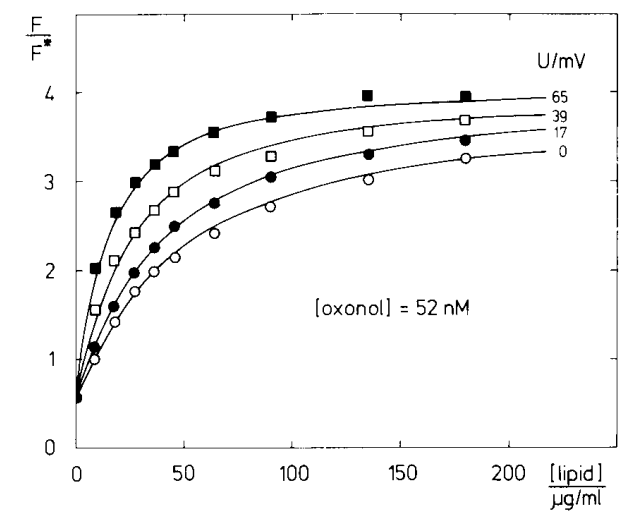

Fig. 7. Fluorescence intensity, $F$, as a function of lipid concentration for different membrane potentials, $U . F^{*}$ is the intensity measured with a fluorescence standard instead of the cuvette. The membrane potential was generated by a $\mathrm{K}^{+}$ concentration gradient in the presence of valinomycin. A suspension of vesicles formed in buffer $\mathrm{H}$ containing $10 \mathrm{mM} \mathrm{K}^{+}$ were diluted with a solution of identical composition to yield the desired lipid concentration. To this solution was added 10 $\mathrm{nM}$ valinomycin. This usually resulted in a small signal change representing a constant offset of the fluorescence signal, $F$ (see text). After the fluorescence signal became constant, the extravesicular $\mathrm{K}^{+}$concentration was increased by successive addition of small amounts of $3 \mathrm{M} \mathrm{KCl}$. The value of $U$ was calculated from Eqns. 4 and 6 with $a=10^{-4}, \sigma=1980$ and $c_{\mathrm{d}}=52 \mathrm{nM}$. The curves have been calculated from Eqn. 3 using the following parameter values: $n / V_{\mathrm{w}}=52 \mathrm{nM}, \rho_{1}=9$ $\mathrm{mg} / \mathrm{ml}, f_{\mathrm{w}}=0.55 \mathrm{nmol}^{-1}, f_{1}=4.1 \mathrm{nmol}^{-1}, \gamma=19000(0 \mathrm{mV})$; $26400(17 \mathrm{mV}) ; 44600(39 \mathrm{mV}) ; 84000(65 \mathrm{mV})$. ions of the model, using again Eqn. 3. As shown by Fig. 7, the experimental results could be satisfactorily described by Eqn. 3 using voltage-independent values of the fluorescence parameters, $f_{\mathrm{w}}$ and $f_{1}$. The only quantity in Eqn. 3 which had to be varied with voltage in order to fit the experimental data was the partition coefficient, $\gamma$. This finding is consistent with the notion that the effect of voltage consists exclusively in changing the fraction of dye molecules which are bound to the membrane, whereas the average environment of a bound dye molecule remains virtually unchanged. With increasing inside-positive potentials, anionic dye molecules accumulate in the intravesicular solution. Since the external aqueous medium has a much larger volume, this leads to a net increase of the amount of bound dye. This increased dyebinding can be described by an apparent partition coefficient $\gamma_{\text {app }}$ which is plotted in Fig. 8 as a function of voltage. A model which describes the voltage dependence of $\gamma_{\text {app }}$ will be discussed later.

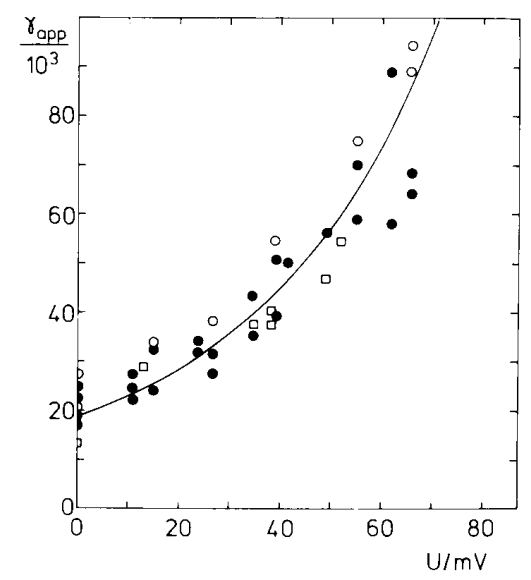

Fig. 8. Apparent partition coefficient, $\gamma_{\text {app }}$, as a function of membrane potential, $U . \gamma_{\text {app }}$ was obtained by fitting Eqn. 3 to the experimental data represented in Fig. 7 and to additional data not shown in Fig. 7. The reconstitution of the $\left(\mathrm{Na}^{+}+\right.$ $\mathrm{K}^{+}$)-ATPase vesicles was carried out with protein/lipid ratio $(w / w)$ of $0.8 / 7.5$. The theoretical curve was calculated from Eqn. 14 using the following parameter values: $\gamma=19000$, $c_{\mathrm{D}}=130 \mathrm{nM}, d=4 \mathrm{~nm}, V^{\prime} / V^{\prime \prime}=10^{4}, V_{\mathrm{w}} \approx V^{\prime \prime}$. See legend of Fig. 7 for further explanations. $\bullet 13 \mathrm{nM}$ Oxonol VI; $\bigcirc, 130$ nM Oxonol VI; $\square, 13 \mathrm{nM}$ Oxonol VI, vesicles containing $\left(\mathrm{Na}^{+}+\mathrm{K}^{+}\right)$-ATPase. 
If the voltage-induced fluorescence change, $\Delta F$, results from a voltage-dependent redistribution of dye between water and membrane, the magnitude of $\Delta F$ should depend on lipid concentration. This is illustrated in Fig. 9, in which the relative fluorescence change, $\Delta F / F_{0} \equiv[F(\mathrm{U})-F(0)] / F(0)$, is plotted as a function of lipid concentration for a membrane calculated from Eqn. 3 with $\gamma_{\text {app }}(U=$ $0)=19000$ and $\gamma_{\text {app }}(U=65 \mathrm{mV})=84000$ taken from Fig. 8. The non-monotonic shape of the $\Delta F / F_{0}$ curve can be understood in the following way. At low lipid concentration the fluorescence signal is dominated by dye molecules dissolved in water, so that $\Delta F / F_{0}$ is small. At high lipid concentration most of the dye is already bound to te lipid meaning that the fluorescence change induced by an inside-positive voltage again is small. The theoretical curve in Fig. 9 agrees with the experimental results, although the scatter of the data points is too large to demonstrate unequiv-

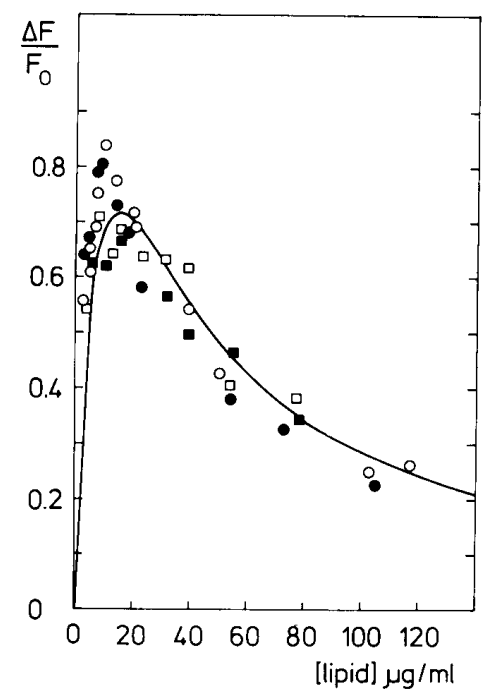

Fig. 9. Fluorescence change, $\Delta F=F(U)-F(0)$, observed after generation of an inside-positive membrane potential of $U=65$ $\mathrm{mV}$, as a function of lipid concentration, $F_{0} \equiv F(0)$ is the fluorescence intensity at zero voltage. The membrane potential, $U$, was created by an extravesicular $\mathrm{K}^{+}$concentration of 140 $\mathrm{mM}$ in the presence of $10 \mathrm{nM}$ valinomycin; the intravesicular $\mathrm{K}^{+}$concentration was $10 \mathrm{mM}$. The value of $U$ was calculated as described in the legend of Fig. 7. [Oxonol] (nM): $\bullet, 62 ; O$, $125 ; \square, 250 ; \square, 500$. ocally the decrease of $\Delta F / F_{0}$ at low lipid concentrations. Calibration of fluorescence changes as a function of
membrane potential

The relative fluorescence change $\Delta F / F_{0} \equiv[F(U)$ $-F(0)] / F(\mathrm{C})$ was measured in the voltage range between 0 and $+120 \mathrm{mV}$ (inside positive). These calibration experiments were carried out in the following way. To a suspension of vesicles with identical $\mathrm{K}^{+}$concentrations in the intra- and extravesicular medium was added $10 \mathrm{nM}$ valinomycin. This resulted in a (usually negative) fluorescence change which was always smaller than $10 \%$. A possible explanation of this signal offset which was only observed with protein-free vesicles consists in the assumption that a small membrane potential is present prior to the addition of valinomycin, which may result from the presence of residual cholate in the inner leaflet of the vesicle membrane [27]. Upon addition of valinomycin, the membrane potential drops to zero, corresponding to the symmetrical $\mathrm{K}^{+}$concentrations on either side of the vesicle membrane. The magnitude of the signal offset varied from vesicle preparation to vesicle preparation; however, when all fluorescence signals were referred to the fluorescence intensity after valinomycin addition, the calibration curves were reproducible.

In order to test whether the observed fluorescence changes are uniquely determined by membrane voltage, calibration experiments were carried out in which the same voltage was generated with different combinations of intra- and extravesicular potassium concentrations, keeping the ratio $c^{\prime} / c^{\prime \prime}$ fixed and maintaining a constant total concentration, $c_{t}$, of $\mathrm{Na}^{+}$plus $\mathrm{K}^{+}$on both sides of the membrane. The result of these experiments is shown in Figs. 10A-C. As seen from Figs. 10A and 10B, the calibration curves measured with intravesicular $\mathrm{K}^{+}$concentrations of 1 and $10 \mathrm{mM}$ are nearly the same, albeit with a small systematic deviation towards lower $\Delta F / F_{0}$ at $c_{0}^{\prime}=1 \mathrm{mM}$. The total concentration of $\mathrm{K}^{+}$plus $\mathrm{Na}^{+}$in Figs. $10 \mathrm{~A}$ and $10 \mathrm{~B}$ was $c_{1}=150 \mathrm{mM}$; in Fig. $10 \mathrm{C}$ are shown experiments in which $c_{\mathrm{t}}$ was varied $\left(c_{\mathrm{t}}=75\right.$, 150 and $300 \mathrm{mM}$ ). It is seen that the calibration curve is not significantly different at the different ionic strengths. Figs. 10A-C further show that the 

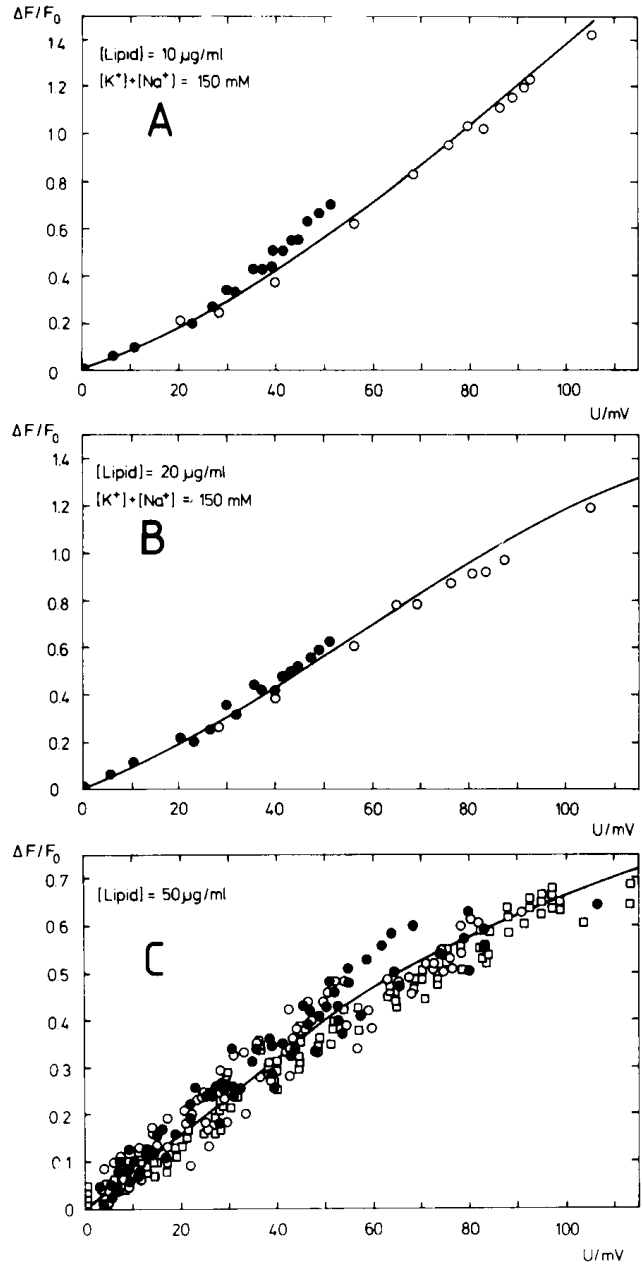

Fig. 10. Relative fluorescence change, $\Delta F / F_{0} \equiv[F(U)-$ $F(0)] / F(0)$, as a function of transmembrane voltage, $U$. The voltage was generated by maintaining a $\mathrm{K}^{+}$concentration gradient across the vesicle membrane in the presence of $10 \mathrm{nM}$ valinomycin. The value of $U$ at a given initial intravesicular $\mathrm{K}^{+}$concentration, $c_{0}^{\prime} \equiv\left[\mathrm{K}^{+}\right]_{\mathrm{i}}^{0}$, was calculated from Eqns. 4 and 6 , neglecting the term proportional to $c_{D}$ in Eqn. 6. the concentrations of Oxonol VI ranged between 125 and $380 \mathrm{nM}$. $T=20^{\circ} \mathrm{C}$. The theoretical curves were calculated from Eqn. 9 with the following parameter values: (A) Lipid concentration $10 \mu \mathrm{g} / \mathrm{ml}$; total concentration, $c_{t}$, of $\mathrm{Na}^{+}+\mathrm{K}^{+}$in the intraand extravesicular medium, $150 \mathrm{mM}$; initial intravesicular $\mathrm{K}^{+}$ concentration, 1 (O) or $10 \mathrm{mM}(\bullet)$. (B) As (A) but lipid concentration $20 \mu \mathrm{mol} / \mathrm{ml}$. (C) Lipid concentration $50 \mu \mathrm{g} / \mathrm{ml}$; $c_{\mathrm{t}}$ variable $(75(\mathrm{O}), 150(\bullet)$ and $300(\square) \mathrm{mM})$; initial intravesicular $\mathrm{K}^{+}$concentrations between 1 and $10 \mathrm{mM}$ calibration depends on lipid concentration, as may have been anticipated from Fig. 9. The continuous curves in Figs. 10A-C have been calculated on the basis of the theoretical model (Eqns. 9 and 14) to be discussed later.

At inside-negative potentials $U$ the fluorescence signal $\Delta F / F_{0}$ tends to saturate already at small values of $U$, below $\approx-40 \mathrm{mV}$, as seen from Fig. 11. It is also seen from Fig. 11 that for $U<0$ the fluorescence signal deviates from the theoretical curve (continuous line) which has been calculated using values of the model parameters determined from experiments at $U>0$. The origin of this discrepancy is not clear so far.

In all experiments described so far, the dye was added to the extravesicular medium. A few experiments were carried out in which the dye was present already in the dialysis medium used for the formation of the vesicles. The same dye concentration $(130 \mathrm{nM})$ was present in the fluorescence cuvette to which the vesicles were added. Under this symmetrical condition with respect to dye concentration, the calibration curve was found to be virtually the same as in the asymmetrical case. This observation is consistent with the assumption (on which the interpretation of our experiments is based) that Oxonol VI equilibrates across the vesicle membrane.

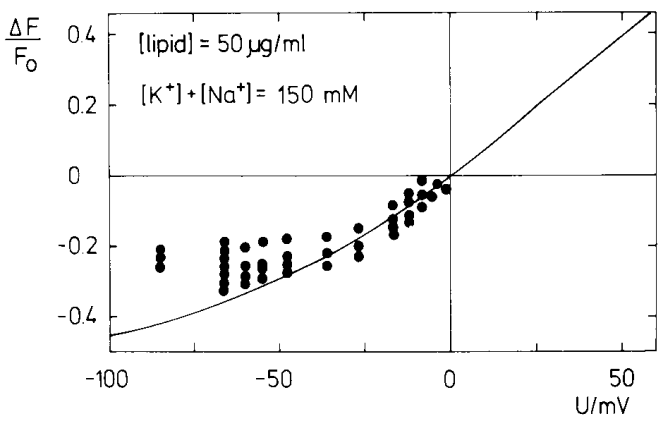

Fig. 11. Relative fluorescence change, $\Delta F / F_{0}$, at inside-negative membrane potentials, $U$. Vesicles loaded with $140 \mathrm{mM} \mathrm{K}^{+}$ were suspended in a medium containing $10 \mathrm{nM}$ valinomycin, $52 \mathrm{nM}$ Oxonol VI and various $\mathrm{K}^{+}$concentrations, $c^{\prime \prime} \leqslant 100$ $\mathrm{mM}$. The total concentration of $\mathrm{Na}^{+}+\mathrm{K}^{+}$in the intra- and extravesicular medium was kept constant at $150 \mathrm{mM}$. The lipid concentration was $50 \mu \mathrm{g} / \mathrm{ml} . T=20^{\circ} \mathrm{C}$ 
Membrane potentials generated by the $\mathrm{Na}^{+}, \mathrm{K}^{+}$. pump

Reconstituted $\left(\mathrm{Na}^{+}+\mathrm{K}^{+}\right)$-ATPase vesicles formed by detergent dialysis contain pump molecules of either orientation $[28,29]$. By adding ATP to the extravesicular medium, only those pumps with an outside-facing ATP-binding site become activated. Since the $\left(\mathrm{Na}^{+}+\mathrm{K}^{+}\right)$-ATPase normally transports $3 \mathrm{Na}^{+}$ions outward and $2 \mathrm{~K}^{+}$ions inward [30], activation of inside-out-oriented pumps should generate an inside-positive membrane potential in the vesicle [24]. An experiment demonstrating this electrogenic effect of the pump is shown in Fig. 12. After addition of $2.5 \mathrm{mM}$ ATP to the vesicle suspension at a temperature of $11^{\circ} \mathrm{C}$, the fluorescence starts to increase, reaching a plateau after about $80 \mathrm{~s}$. From the plateau value of $\Delta F / F_{0}(\approx 0.8)$ and the calibration curve for 35 $\mu \mathrm{g} / \mathrm{ml}$ lipid, the maximum voltage is estimated to be about $90 \mathrm{mV}$ (inside positive). When vanadate, a potent inhibitor of the $\mathrm{Na}^{+}, \mathrm{K}^{+}$-pump [30] is added to the medium, the signal declines, approaching an asymptotic value with a time constant of about $200 \mathrm{~s}$. (The fact that the fluorescence intensity drops below the starting value may result from a change of interfacial potential by

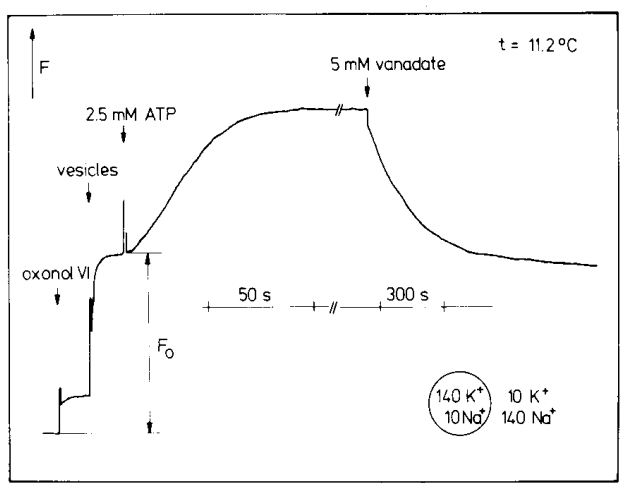

Fig. 12. Membrane potential generated by the $\mathrm{Na}^{+}, \mathrm{K}^{+}$-pump Vesicles were reconstituted in buffer $\mathrm{H}$ containing $140 \mathrm{mM} \mathrm{K}^{+}$ and $10 \mathrm{mM} \mathrm{Na}^{+}$, as described before [24] and suspended in buffer $\mathrm{H}$ containing $140 \mathrm{mM} \mathrm{Na}^{+}$and $10 \mathrm{mMK}^{+}$. The average number of pump molecules with the ATP-binding site facing outward was determined to be $n \approx 1.52 \mathrm{nM}$ Oxonol VI, 35 $\mu \mathrm{g} / \mathrm{ml}$ lipid, $2.5 \mathrm{mM}$ ATP and $5 \mathrm{mM}$ vanadate were successively added. $F$ is the fluorescence intensity. The temperature was $11.2^{\circ} \mathrm{C}$ vanadate binding, as reflected by the fast fluorescence change upon vanadate addition.) The decline of fluorescence intensity is likely to result from a decay of membrane voltage via the leakage conductance of the vesicle membrane. If this is true, then the time constant, $\tau$, should be equal to $C_{\mathrm{m}} / G_{\mathrm{m}}$, where $C_{\mathrm{m}}$ and $G_{\mathrm{m}}$ are the specific capacitance and the specific conductance of the membrane, respectively. With $\tau \approx 200 \mathrm{~s}$ and $C_{\mathrm{m}} \approx 1$ $\mu \mathrm{F} / \mathrm{cm}^{2}, G_{\mathrm{m}}$ becomes about $5 \mathrm{nS} / \mathrm{cm}^{2}$, which is reasonable value for a lipid bilayer [31]. From the initial slope of $\Delta F / F_{0}$ versus time $t$ in Fig. 12, the initial rate of voltage change can be estimated to be $\mathrm{d} U / \mathrm{d} t \approx 1.75 \mathrm{mV} \cdot \mathrm{s}^{-1}$ which must be equal to $n e_{0} v_{0} / A C_{\mathrm{m}}$ where $n$ is the average number of (outward oriented) pump molecules per vesicle, $e_{0}$ the elementary charge, $v_{0}$ the initial turnover rate and $A$ the average area of the vesicle membrane. In the vesicle preparation used for the experiment of Fig. 12, $n$ was determined from the potassium flux rate [24] to be about 1 . This yields, with $A \approx 0.025 \mu \mathrm{m}^{2}$ and $e_{0} \approx 1.6 \cdot 10^{-19} \mathrm{C}$, an initial turnover rate of $v_{0}=A C_{\mathrm{m}}(\mathrm{d} U / \mathrm{d} t) / n_{0} \approx 2.8 \mathrm{~s}^{-1}$. On the other hand, if $v$ is the turnover rate in the quasi-stationary state in which the pump current is compensated by a backflow of charge through the membrane conductance $G_{\mathrm{m}}$, the relation $n e_{0} v$ $=A G_{\mathrm{m}} U_{\mathrm{s}}$ holds where $U_{\mathrm{s}} \approx 90 \mathrm{mV}$ is the stationary voltage. This gives $v=0.058 \mathrm{~s}^{-1}$. Thus, the turnover rate, $v$, in the quasi-stationary state is about 50-times smaller than the initial turnover rate, $v_{0}$. The difference between $v$ and $v_{0}$ is likely to reflect the voltage dependence of pumping rate [32].

When the experiment is carried out at a higher temperature $\left(18^{\circ} \mathrm{C}\right)$, the initial rate of fluorescence change after ATP addition is much increased (Fig. 13). The fluorescence signal, $F$, maintains its plateau value only for a short time and then declines toward a much lower level. A likely explanation of the decline of $F$ lies in the assumption that ATP-driven potassium extrusion results in a progressive reduction of intravesicular $\mathrm{K}^{+}$concentration which eventually leads to an inhibition of the pump followed by a decay of voltage via leakage pathways. From Figs. 13 and 10 the initial rate of voltage change may be estimated to be about $10 \mathrm{mV} \cdot \mathrm{s}^{-1}$, corresponding, for a spherical vesicle of internal radius $r=40 \mathrm{~nm}$, to 


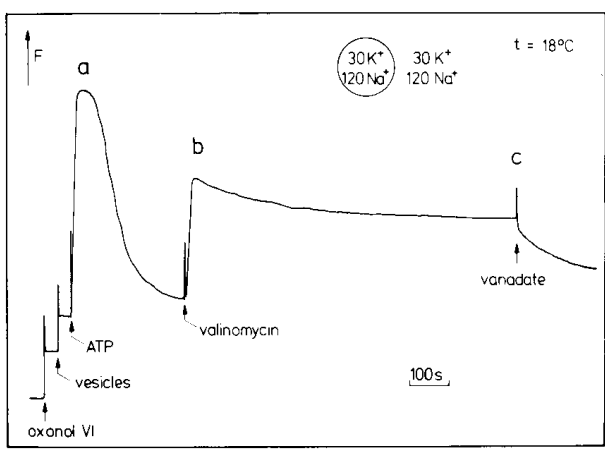

Fig. 13. Membrane potential generated by the $\mathrm{Na}^{+}, \mathrm{K}^{+}$-pump. Vesicles were reconstituted in buffer $\mathrm{H}$ containing $30 \mathrm{mM} \mathrm{K}$ and $120 \mathrm{mM} \mathrm{Na}^{+}$and suspended in the same medium. $13 \mathrm{mM}$ Oxonol VI, $8 \mu \mathrm{g} / \mathrm{ml}$ lipid, $2.5 \mathrm{mM}$ ATP, $10 \mathrm{nM}$ valinomycin and $5 \mathrm{mM}$ vanadate were added successively. $T=18^{\circ} \mathrm{C}$. a, b and $c$ have been estimated to be about 160,100 and $75 \mathrm{mV}$, respectively.

a $\mathrm{K}^{+}$-depletion rate of $\left(3 C_{\mathrm{m}} / e_{0} r\right) \cdot \mathrm{d} U / \mathrm{d} t \approx 0.2$ $\mathrm{mM} \cdot \mathrm{s}^{-1}$ (assuming that two $\mathrm{K}^{+}$ions are extruded per turnover). This means that the intravesicular $\mathrm{K}^{+}$-concentration would drop within about $150 \mathrm{~s}$ from the initial value of $30 \mathrm{mM}$ to nearly zero if the pumping rate $v$ were to retain its initial value for this period of time. In reality, pumping is slowed down by the opposing effect of transmembrane voltage, which tends to increase the depletion time, $t^{*}$. The fact that the estimated value of $t^{*}$ agrees approximately with the duration of the quasi-stationary period in Fig. 13 is consistent with the assumption that the decay of the fluorescence signal results from $\mathrm{K}^{+}$depletion of the vesicle. This assumption is further supported by the finding that, upon addition of valinomycin, the fluorescence increases again (Fig. 13), indicating the presence of an inward directed $\mathrm{K}^{+}$-concentration gradient.

The relative fluorescence change, $\Delta F / F_{0}$, at the plateau of the fluorescence signal in Fig. 13 is about 2.7. Since this value exceeds the range of the calibration curve (Fig. 10), the voltage $U$ corresponding to $\Delta F / F_{0}$ can only be estimated on the basis of the theoretical calibration curve calculated by fitting the model parameters to the experimental data at lower voltage. In this way the voltage at the plateau of $F$ in Fig. 13 is estimated to be approx. $160 \mathrm{mV}$.

The initial rate of fluorescence change after ATP addition has been measured at different temperatures. Using the calibration curve, the density of active pump molecules per vesicle and accounting for the membrane capacitance, the initial pumping rate, $v_{0}$, can be evaluated as a function of temperature. The results are plotted in Fig. 14 in the form of an Arrhenius diagram. From the slope of $\ln v_{0}$ vs. $1 / T$ the activation energy of the pump current is determined to be $E_{\mathrm{a}} \approx 160 \mathrm{~kJ}$. $\mathrm{mol}^{-1}$. Implicit in the determination of $E_{\mathrm{a}}$ is the assumption that the redistribution of the dye across the vesicle membrane is not rate limiting.

Under similar conditions the activation energy of the turnover rate was experimentally determined to be $115 \mathrm{~kJ} / \mathrm{mol}$ using an indocyanine dye as potential indicator [24]. In order to test for a possible influence of Oxonol VI on the activation energy a number of control experiments was performed. In a first series of experiments the enzymatic activity of reconstituted $\left(\mathrm{Na}^{+}+\mathrm{K}^{+}\right)$-

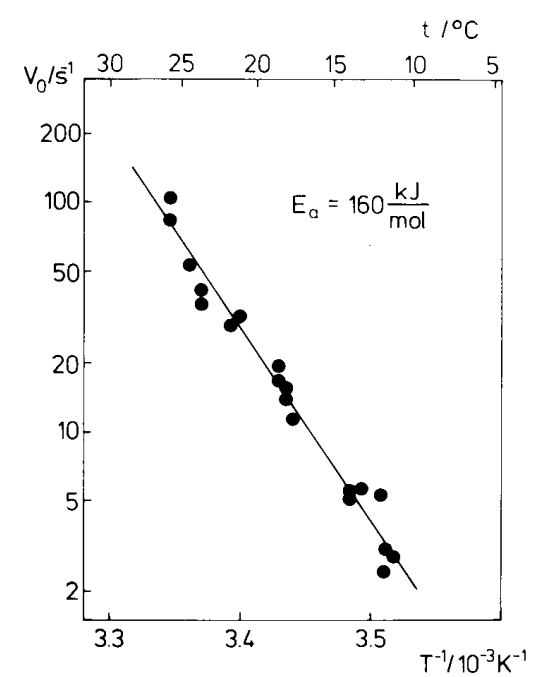

Fig. 14. Initial pumping rate, $v_{0}$ (referred to unit membrane area), as a function of reciprocal temperature. $v_{0}$ has been estimated from the initial rate of fluorescence change after ATP addition using the calibration curve (Fig. 10) and accounting for the membrane capacitance. $E_{\mathrm{a}}$ is the activation energy obtained from the Arrhenius relation. 
ATPase was checked in the presence of different concentrations of Oxonol VI. At aqueous dye concentrations lower than $500 \mathrm{nM}$ the enzymatic activity measured by the pyruvate kinase/lactate dehydrogenase assay [35] was not significantly influenced. In a second series of experiments, vesicles (with and without enzyme) containing 10 $\mathrm{mM} \mathrm{K}^{+}$were diluted in an isoosmolar buffer with $140 \mathrm{mM} \mathrm{K}^{+}$. Upon addition of valinomycin, the fluorescence signals increased to reach the level of the Nernst potential. The initial rate of fluorescence change was recorded at different temperatures. No significant temperature dependence was found in the range between $8^{\circ} \mathrm{C}$ and $25^{\circ} \mathrm{C}$. At $15^{\circ} \mathrm{C}$ and a valinomycin concentration of $20 \mathrm{nM}$ the initial rate of voltage change was found to be about $30 \mathrm{mV} / \mathrm{s}$. This rate is large compared to the rate of voltage rise observed after pump activation by ATP.

Marcus et al. [36] found strong effects of chain length and of the number of double bonds in the fatty-acid residue of the lipid onto the activation energy of reconstituted $\left(\mathrm{Na}^{+}+\mathrm{K}^{+}\right)$-ATPase. These findings suggest a possible explanation of the increased activation energy. Oxonol VI, which is contained in the membrane in a ratio of $1 / 500$ to $1 / 100$ dyes per lipid molecules, could include a 'cholesterol-like' effect on membrane rigidity, or it may alter membrane thickness and interfere in this way with pumping activity.

\section{Discussion}

The results presented in this study show that the effect of transmembrane voltage on fluorescence of Oxonol VI in a vesicle suspension can be understood on the basis of a simple model. The experiments carried out at zero voltage indicated that a partition equilibrium exists between dye in water and dye adsorbed to the membrane. Upon adsorption, the fluorescence (at an excitation wavelength of $580 \mathrm{~nm}$ ) increases by a factor of $4.1 / 0.55 \approx 7.4$. With a partition coefficient $\gamma \approx$ 19000 , a substantial fraction of the dye is bound to the membrane at lipid concentrations of the order of $10-100 \mu \mathrm{g} / \mathrm{ml}$. In the presence of an inside-positive membrane potential, the negatively charged dye accumulates in the intravesicular aqueous space according to a Nernst equilibrium.
This leads to an increased adsorption of dye to the inner lipid monolayer and to a concomitant increase of fluorescence. This mechanism which has been previously discussed in the literature $[14,15,19]$ is strongly supported by the quantitative analysis described in this paper.

Voltage dependence of the apparent partition coefficient

From the analysis of voltage-induced fluorescence changes as a function of lipid concentration (Fig. 7) it is found that the intrinsic fluorescence, $f_{1}$, of the membrane-bound dye is voltage-independent. The whole effect of voltage on the fluorescence $F$ of the vesicle suspension can be described by a voltage-dependent apparent partition coefficient $\gamma_{\text {app }}$ which enters into Eqn. 3:

$F=n \frac{f_{\mathrm{w}} V_{\mathrm{w}}+\gamma_{\mathrm{app}} f_{1} V_{1}}{V_{\mathrm{w}}+\gamma_{\mathrm{app}} V_{1}}$

In the following, we show that the experimentally observed voltage-dependence of $\gamma_{\text {app }}$ (Fig. 8) can be quantitatively described by the three-capacitor model depicted in Fig. 15, which has previously been used in the analysis of adsorption of lipophilic ions to lipid bilayers $[34,35]$. The dye is

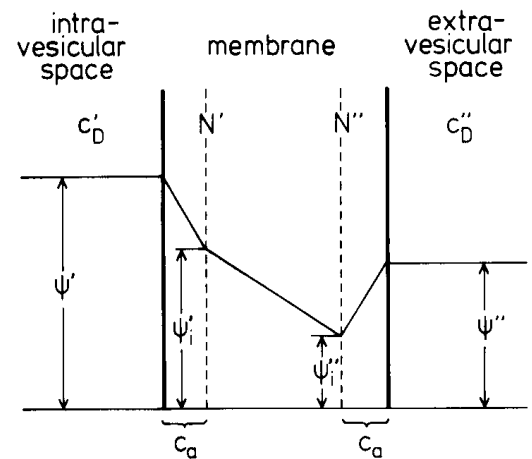

Fig. 15. Three-capacitor model used in analyzing the voltage dependence of the apparent partition coefficient $\gamma_{\text {app }}$. The dye is assumed to adsorption planes located symmetrically with respect to the centre of the membrane. $C_{a}$ is the electrical capacitance between the adsorption plane and the adjacent aqueous solution. $c_{\mathrm{D}}^{\prime}$ and $c_{\mathrm{D}}^{\prime \prime}$ are the aqueous dye concentrations. $\psi^{\prime}, \psi_{i}^{\prime}, \psi_{i}^{\prime \prime}$ and $\psi^{\prime \prime}$ the electric potentials, and $N^{\prime}$ and $N^{\prime \prime}$ the surface concentrations of bound dye. 
assumed to bind to adsorption planes located on the hydrocarbon side of the membrane/solution interface. The surface concentrations, $N^{\prime}$ and $N^{\prime \prime}$, of bound dye (Fig. 15) which are referred to unit membrane area are given by

$N^{\prime}=\beta^{\prime} \cdot c_{\mathrm{D}}^{\prime}, \quad N^{\prime \prime}=\beta^{\prime \prime} \cdot c_{\mathrm{D}}^{\prime \prime}$

where $c_{\mathrm{D}}^{\prime}$ and $c_{\mathrm{D}}^{\prime \prime}$ are the aqueous dye concentrations. If $\psi^{\prime}$ and $\psi^{\prime \prime}$ are the electrical potentials in the intra- and extravesicular space and $\psi_{i}^{\prime}$ and $\psi_{i}^{\prime \prime}$ the potentials in the adsorption planes (Fig. 15), the voltage dependence of the interfacial partition coefficients, $\beta^{\prime}$ and $\beta^{\prime \prime}$, may be expressed by

$$
\begin{array}{ll}
\beta^{\prime}=\beta \exp \left(-u^{\prime}\right) ; & \beta^{\prime \prime}=\beta \exp \left(-u^{\prime \prime}\right) \\
u^{\prime} \equiv F\left(\psi^{\prime}-\psi_{\mathrm{i}}^{\prime}\right) / R T ; & u^{\prime \prime} \equiv F\left(\psi^{\prime \prime}-\psi_{\mathrm{i}}^{\prime \prime}\right) / R T
\end{array}
$$

$\beta$ is the value of $\beta^{\prime}$ and $\beta^{\prime \prime}$ at zero voltage. The dimensionless voltages, $u^{\prime}$ and $u^{\prime \prime}$, can be numerically evaluated on the basis of the three-capacitor model, as described in Appendix B. Since under equilibrium conditions $\left(U=0, c_{\mathrm{D}}^{\prime}=c_{\mathrm{D}}^{\prime \prime}=c_{\mathrm{D}}\right)$ the relation $\left(N^{\prime}+N^{\prime \prime}\right) / d=\gamma c_{\mathrm{D}}$ holds, $\beta$ and $\gamma$ are connected by

$\beta=\gamma d / 2$

with membrane thickness $d(\approx 4 \mathrm{~nm})$.

The fluorescence, $F$, of the vesicle suspension may be calculated introducing the relations $n_{\mathrm{w}}=$ $c_{\mathrm{D}}^{\prime} V^{\prime}+c_{\mathrm{D}}^{\prime \prime} V^{\prime \prime}$ and $n_{1}=n-n_{\mathrm{w}}=A\left(N^{\prime}+N^{\prime \prime}\right)$ into Eqn. 2 ( $A$ is the total membrane area and $V^{\prime}$ and $V^{\prime \prime}$ are the volumes of the intra- and extravesicular space). Together with the Nernst relation $c_{\mathrm{D}}^{\prime} / c_{\mathrm{D}}^{\prime \prime}=\exp (F U / R T) \equiv \exp (u)$, the fluorescence intensity, $F$, is obtained in the form of Eqn. 9, where $\gamma_{\text {app }}$ is given by

$\gamma_{\text {app }} \equiv \frac{\left(N^{\prime}+N^{\prime \prime}\right) / d}{\left(c_{\mathrm{D}}^{\prime} V^{\prime}+c_{\mathrm{D}}^{\prime \prime} V^{\prime \prime}\right) / V_{\mathrm{w}}}=\frac{\gamma V_{\mathrm{w}}}{2} \cdot \frac{\exp \left(u-u^{\prime}\right)+\exp \left(-u^{\prime \prime}\right)}{V^{\prime} \exp (u)+V^{\prime \prime}}$

In the limit $c_{\mathrm{D}} \rightarrow 0, u^{\prime}$ and $u^{\prime \prime}$ in Eqns. 11 and 14 reduce to $u^{\prime} \approx-u^{\prime \prime} \approx\left(C_{\mathrm{m}} / C_{\mathrm{a}}\right) u$ (Appendix B). Since $\gamma, V_{\mathrm{w}}, V^{\prime}$ and $V^{\prime \prime} \approx V_{\mathrm{w}}$ are known, Eqn. 14 can be fitted to the experimentally observed voltage dependence of $\gamma_{\text {app }}$ (Fig. 8) using the numerically evaluated values of $u^{\prime}$ and $u^{\prime \prime}$ which depend on the capacitance $C_{\mathrm{a}}$ (Fig. 15). It is seen from Fig. 8 that the theoretical curve which has been calculated with $\alpha \equiv C_{\mathrm{a}} / C_{\mathrm{m}}=0.2$ adequately described the experimental data. The value of $\alpha=0.2$ indicates that the adsorption plane is located away from the interface towards the hydrophobic interior of the membrane. This is consistent with the finding from ${ }^{31} \mathrm{P}-\mathrm{NMR}$ experiments that Oxonol VI does not perturb the local motion of the phosphate group in phosphatidylcholine bilayers [20]. Eqns. 9 and 14 can also be used to fit the calibration curves, as shown by the theoretical curves in Figs. 10A-C.

\section{Experiments with $\left(\mathrm{Na}^{+}+\mathrm{K}^{+}\right)$-ATPase vesicles}

Oxonol VI was found to be suitable for detecting changes of membrane potential associated with the activity of the $\mathrm{Na}^{+}, \mathrm{K}^{+}$-pump in reconstituted vesicles. When ATP is added to the external medium, pump molecules with the ATP-binding site facing outward become activated, which results in a translocation of net positive charge towards the vesicle interior. Under this condition large fluorescence changes are observed corresponding to inside-positive potentials of up to 150-200 mV. After the build-up of the membrane potential, a quasi-stationary state is reached in which the pump current is compensated by a back-flow of charge through passive conductance pathways. Experiments of this kind may be used for studying the current-voltage behaviour of the $\mathrm{Na}^{+}, \mathrm{K}^{+}$-pump.

\section{Concluding remarks}

From the foregoing analysis, a number of conclusions concerning the application of Oxonol VI for voltage measurements can be drawn. Since Oxonol VI distributes between intra- and extravesicular medium according to a Nernst equilibrium, inside-positive potentials can lead to a strong accumulation of the anionic dye and to high concentrations of bound dye in the inner lipid monolayer. This means that the simple mechanism discussed here for the dependence of optical properties on voltage can be operative only at sufficiently low dye concentrations. At high dye concentrations $\left(c_{\mathrm{D}}>1 \mu \mathrm{M}\right)$ additional phenomena, such as aggregation of dye molecules and self- 
quenching of fluorescence, may be expected [15].

For an optimum voltage-response of the dye, the vesicle concentration is critical, as shown by Fig. 9. The optimum lipid concentration (which is independent of dye concentration) is found to be about $10-20 \mu \mathrm{g} / \mathrm{ml}$. Calibration of the fluorescence signal as a function of voltage is meaningful only at a well-defined lipid concentration.

The response time of Oxonol VI after a fast voltage change is limited by the permeation rate of the dye across the membrane. In our experiments the response time was limited by the mixing time of reagents in the fluorescence cuvette and was less than $3 \mathrm{~s}$. In experiments with bacterial chromatophores [14] Oxonol VI was found to respond in the time range of milliseconds to a light-induced change of membrane potential.

\section{Appendix A}

Derivation of Eqn. 6

We assume that initially the intra- and extravesicular $\mathrm{K}^{+}$concentrations are $c_{0}^{\prime}$ and $c_{0}^{\prime \prime}$, respectively, and that the membrane potential is zero. Upon addition of valinomycin and Oxonol $\mathrm{VI}, \mathrm{K}^{+}$ions and dye anions move inward. After equilibration, the potassium concentrations in the intra- and extravesicular space are $c^{\prime}$ and $c^{\prime \prime}$. Since the total amount of $\mathrm{K}^{+}$in the system remains constant, the relation

$c^{\prime} V^{\prime}+c^{\prime \prime} V^{\prime \prime}=c_{0}^{\prime} V^{\prime}+c_{0}^{\prime \prime} V^{\prime \prime}$

holds, where $V^{\prime}$ and $V^{\prime \prime}$ are the volumes of the intra- and extravesicular aqueous spaces. Similarly, if $c_{\mathrm{D}} V^{\prime \prime}$ is the total amount of dye which is initially added to the medium, the relation

$c_{\mathrm{D}} V^{\prime \prime}=c_{\mathrm{D}}^{\prime} V^{\prime}+c_{\mathrm{D}}^{\prime \prime} V^{\prime \prime}+\frac{d}{2} A \gamma\left(c_{\mathrm{D}}^{\prime}+c_{\mathrm{D}}^{\prime \prime}\right)$

is fulfilled. $c_{\mathrm{D}}^{\prime}$ and $c_{\mathrm{D}}^{\prime \prime}$ are the dye concentrations in the intra- and extravesicular solutions after equilibration, $A$ is the total membrane area, and $d$ is the membrane thickness; the factor $(d / 2) A \gamma\left(c_{\mathrm{D}}^{\prime}\right.$ $\left.+c_{\mathrm{D}}^{\prime \prime}\right)$ accounts for dye binding to either membrane/solution interface ( $\gamma$ is the partition coefficient defined by Eqn. 1). Implicit in Eqn. A-2 is the assumption that the partition equilibrium at the interface is voltage-independent; this assumption is only approximately fulfilled, as discussed previously. We further assume that effects of electrical double-layers can be neglected in the presence of a sufficiently high concentration of inert electrolyte, and that the only permeable ion species (after addition of valinomycin) are $\mathrm{K}^{+}$and the dye anion. After equilibration, the membrane potential is given by

$U \equiv \psi^{\prime}-\psi^{\prime \prime}=\frac{R T}{F} \ln \frac{c^{\prime \prime}}{c^{\prime}}=\frac{R T}{F} \ln \frac{c_{\mathrm{D}}^{\prime}}{c_{\mathrm{D}}^{\prime \prime}}$

In order to build up this voltage, a charge $Q=$ $A C_{\mathrm{m}} U$ has to move across the membrane ( $A$ is the total membrane area, and $C_{\mathrm{m}}$ is the specific membrane capacitance). $Q$ is given by the number of $\mathrm{K}^{+}$ions and dye anions which have entered the intravesicular aqueous space; an additional contribution to $Q$ results from dye anions which became adsorebd to the inner membrane interface:

$Q=F\left[\left(c^{\prime}-c_{0}^{\prime}\right) V^{\prime}+c_{\mathrm{D}}^{\prime} V^{\prime}-c_{\mathrm{D}}^{\prime} A \gamma d / 2\right]$

This gives, together with $Q=A C_{\mathrm{m}} U$ :

$c^{\prime}=c_{0}^{\prime}+C^{*} \ln \frac{c^{\prime \prime}}{c^{\prime}}+c_{\mathrm{D}}^{\prime}(l+\sigma)$

$C^{*} \equiv R T A C_{\mathrm{m}} / F^{2} V^{\prime}$

$\sigma \equiv \gamma A d / 2 V^{\prime}=\gamma V_{1} / 2 V^{\prime}$

$V_{1}$ is the volume of the lipid phase. Eqns. A-1-A-5 together yield:

$c^{\prime \prime}=c_{0}^{\prime \prime}-a\left(c^{\prime}-c_{0}^{\prime}\right) ; \quad a \equiv V^{\prime} / V^{\prime \prime}$

$c^{\prime}=c_{0}^{\prime}+C^{*} \ln \frac{c^{\prime \prime}}{c^{\prime}}+\frac{(1+\sigma) c_{\mathrm{D}} c^{\prime \prime}}{(1+\mathrm{a} \sigma) c^{\prime}+a(1+\sigma) c^{\prime \prime}}$

Eqn. A-8 and A-9 may be further simplified, since in the experiments described here, the volume of the intravesicular aqueous space is only a negligible fraction of the total volume. For a spherical vesicle of internal radius, $r$, and membrane thickness, $d$, the relation $a=y_{1} r / 3 \rho_{1} d$ holds, where $y_{1}$ and $\rho_{1}$ are the mass concentration and the density of the lipid, respectively. With $r \approx 50 \mathrm{~nm}, d \approx 5$ $\mathrm{nm}, \rho_{1} \approx 1 \mathrm{~g} / \mathrm{cm}^{3}$ and $y_{1}=200 \mu \mathrm{g} / \mathrm{cm}^{3}$ (corresponding to the highest experimental lipid concentration), becomes of the order of $10^{-3}$. This means that $c^{\prime \prime} \approx c_{0}^{\prime \prime}$. 


\section{Appendix B}

Boundary potentials generated by dye adsorption

When negatively-charged dye molecules bind to adsorption planes located on the hydrophobic side of the membrane/solution interface, boundary potentials are created. If $\psi_{i}^{\prime}$ and $\psi_{i}^{\prime \prime}$ are the electrical potentials in the adsorption planes and $\psi^{\prime}$ and $\psi^{\prime \prime}$ the potentials in the aqueous solutions (Fig. 15), the surface concentrations $N^{\prime}$ and $N^{\prime \prime}$ of dye molecules are given by

$N=\beta \exp \left(-u^{\prime}\right) c_{\mathrm{D}}^{\prime} ; u^{\prime} \equiv \frac{\psi^{\prime}-\psi_{\mathrm{i}}^{\prime}}{R T / F}$

$N^{\prime \prime}=\beta \exp \left(-u^{\prime \prime}\right) c_{\mathrm{D}}^{\prime \prime} ; u^{\prime \prime} \equiv \frac{\psi^{\prime \prime}-\psi_{\mathrm{i}}^{\prime \prime}}{R T / F}$

$\beta$ is the interfacial partition coefficient and $c_{\mathrm{D}}^{\prime}$ and $c_{\mathrm{D}}^{\prime \prime}$ are the aqueous concentrations of the dye anion which are related by the Nernst equation:

$\frac{c_{\mathrm{D}}^{\prime}}{c_{\mathrm{D}}^{\prime \prime}}=\exp \left(\frac{\psi^{\prime}-\psi^{\prime \prime}}{R T / F}\right) \equiv \exp (u)$

On the basis of the three-capacitor model $[33,34]$ depicted in Fig. 15, the voltages $u^{\prime}, u^{\prime \prime}$ and $u$ are related to the charge densities $q^{\prime}$ and $q^{\prime \prime}$ in the adsorption planes:

$q_{\mathrm{i}}^{\prime}=-F N^{\prime}=\frac{R T}{F}\left(C_{\mathrm{i}} u_{\mathrm{i}}-C_{\mathrm{a}} u^{\prime}\right)$

$q_{\mathrm{i}}^{\prime \prime}=-F N^{\prime \prime}=\frac{R T}{F}\left(C_{\mathrm{a}} u^{\prime \prime}-C_{\mathrm{i}} u_{\mathrm{i}}\right)$

$u \equiv F\left(\psi^{\prime}-\psi^{\prime \prime}\right) / R T$

$C_{\mathrm{a}}$ is the capacitance between adsorption plane and aqueous phase and $C_{\mathrm{i}}$ is the capacitance between the adsorption planes. $C_{\mathrm{a}}$ and $C_{\mathrm{i}}$ are related to the total membrane capacitance, $C_{\mathrm{m}}$, by

$\frac{1}{C_{\mathrm{m}}}=\frac{2}{C_{\mathrm{a}}}+\frac{1}{C_{\mathrm{i}}}$

The total amount, $n$, of dye in the vesicle suspension is given by

$n=c_{\mathrm{D}}^{\prime} V^{\prime}+c_{\mathrm{D}}^{\prime \prime} V^{\prime \prime}+A\left(N^{\prime}+N^{\prime \prime}\right)$

$V^{\prime}$ and $V^{\prime \prime}$ are the volumes of the intra- and extravesicular aqueous solutions and $A$ is the total membrane area. Replacing $\beta$ by the partition coefficient $\gamma$ according to $\beta=\gamma d / 2=\gamma V_{1} / 2 A\left(V_{1}\right.$ is the total volume of the lipid) and using Eqns. B-1-B-8, one obtains

$$
\begin{aligned}
& \frac{\gamma n d}{2 N_{0}} \cdot \frac{(1-2 \alpha) \exp \left(u-u^{\prime}\right)}{V^{\prime} \exp (u)+V^{\prime \prime}+\gamma V_{1}\left[\exp \left(u-u^{\prime}\right)+\exp \left(-u^{\prime \prime}\right)\right] / 2} \\
& \quad=-u+u^{\prime \prime}+\frac{1-\alpha}{\alpha} u^{\prime}
\end{aligned}
$$

$\frac{\gamma n d}{2 N_{0}} \cdot \frac{(1-2 \alpha) \exp \left(-u^{\prime \prime}\right)}{V^{\prime} \exp (u)+V^{\prime \prime}+\gamma V_{\mathrm{l}}\left[\exp \left(u-u^{\prime}\right)+\exp \left(-u^{\prime \prime}\right)\right] / 2}$

$$
\begin{gathered}
=u-u^{\prime}+\frac{1-\alpha}{\alpha} u^{\prime \prime} \\
\alpha \equiv C_{\mathrm{a}} / C_{\mathrm{m}} ; \quad N_{0} \equiv R T C_{\mathrm{rn}} / F^{2}
\end{gathered}
$$

Eqns. B-9 and B-10 can be used for numerical evaluation of the boundary potentials, $u^{\prime}$ and $u^{\prime \prime}$, which enter into the expression for the apparent partition coefficient $\gamma_{\text {app }}$ (Eqn. 14). In the limit of low dye concentration $(n \rightarrow 0)$, Eqns. B-9 and B-10 reduce to

$$
u^{\prime} \approx-u^{\prime \prime} \approx \alpha u
$$

as expected.

\section{Acknowledgements}

The authors are indebted to Dr. P. Läuger for his interest, stimulating and supporting discussions and his help in preparing this manuscript. This work has been financially supported by the Deutsche Forschungsgemeinschaft (Sonderforschungsbereich 156).

\section{References}

1 Bashford, C.L., Smith, J.C. (1978) Methods Enzymol. 55, 569-586

2 Waggoner, A.S. (1979) Annu. Rev. Biophys. Bioeng. 8, $47-68$

3 Freedman, J.C. and Laris, P.C. (1981) Int. Rev. Cytol, Suppl. 12, 177-246

4 Waggoner, A.S. (1985) in The Enzymes of Biological Membranes, 2nd Edn. (Martonosi, A.N., ed.), Vol. 3, pp. 313-331, Plenum Press, New York

5 Smith, J.C., Russ, P., Cooperman, B.S. and Chance, B. (1976) Biochemistry 15, 5094-5105

6 Waggoner, A.S., Wang, C.H. and Tolles, R.L. (1977) J. Membrane Biol. 33, 109-140 
7 Bashford, C.L., Chance, B., Smith, J.C. and Yoshida, T (1979) Biophys. J. 25, 63-85

8 Bashford, C.L. and Thayer, W.S. (1977) J. Biol. Chem. 252 $8459-8463$

9 Pringle, M.J. and Sanadi, D.R. (1984) Membrane Biochem. $5,225-241$

10 Smith, J.C. and Chance, B. (1979) J. Membrane Biol. 46 $255-282$

11 Smith, J.C., Hallidy, L. and Topp, M.R. (1981) J. Membrane Biol. 60, 173-185

12 Schuurmans, J.J., Casey, R.P. and Kraayenhof, R. (1978) FEBS Lett 94, 405-409

13 Admon, A., Shahak, Y. and Avron, M. (1982) Biochim. Biophys. Acta 681, 405-411

14 Bashford, C.L., Chance, B. and Prince, R.C. (1979) Biochim. Biophys. Acta 545, 46-57

15 Beeler, T.J., Farmen, R.H. and Martonosi, A.N. (1981) J. Membrane Biol. 62, 113-137

16 Scherman, D. and Henry, J.P. (1980) Biochim. Biophys. Acta 599, 150-166

17 Perlin, D.S., Kasamo, K., Brookers, R.J. and Slayman, C.W. (1984) J. Biol. Chem. 259, 7884-7892

18 Rasi-Caldogno, F., Pugliarello, M.Ch. and De Michelis, M.I. (1985) Plant Physiol. 77, 200-205

$19 \mathrm{Krab}$, K., Van Walraven, J.S., Scholts, M.J.C. and Kraayenhof, R. (1985) Biochim. Biophys. Acta 809, 228-235

20 Bammel, B.P., Brand, J.A., Simmons, R.B., Evans, D.F and Smith, J.C. (1987) Biochim. Biophys. Acta 896, 136-152

21 Navarro, J. and Essig, A. (1984) Biophys. J. 46, 709-717

22 Van Walraven, H.S., Krab, K., Hagendoorn, M.J.M. and Kraayenhof, R. (1985) FEBS Lett. 184, 96-99
23 Waggoner, A.S. (1976) J. Membrane Biol. 27, 317-334 24 Apell, H.-J., Marcus, M.M., Anner, B.M., Oetliker, H. and Läuger, P. (1985) J. Membrane Biol. 85, 49-63

25 Jørgensen, P.L. (1974) Methods Enzymol. 32, 277-290

26 Anner, B.M., Marcus, M.M. and Moosmayer, M. (1984) in Enzymes, Receptors and Carriers of Biomembranes (Azzi, A., Brodbeck, U. and Zahler, P., eds.), p. 81-99, Springer Verlag, Heidelberg

27 Ueno, M., Tanford, C. and Reynolds, J.A. (1984) Biochemistry $23,3070-3076$

28 Anner, B.M. (1985) Biochim. Biophys. Acta 832, 319-334 29 Anner, B.M (1985) Biochim. Biophys. Acta 832, 335-353

30 Glynn, I.M. (1985) in The Enzymes of Biological Membranes, 2nd Edn. (Martonosi, A.N., ed.), Vol. 3, pp. 35-114, Plenum Press, New York

31 Hanai, T., Haydon, D.A. and Taylor, J. (1964) Proc. R. Soc. London, Ser. A 281, 377-391

32 Läuger, P. and Apell, H.-J. (1986) Eur. Biophys. J. 13 309-321

33 Markin, V.S., Grigorev, P.A. and Yermishkin, L.N. (1971) Biofizika 16, 1011-1018

34 Andersen, O.S., Feldberg, S., Nakadomari, H., Levy, S. and McLaughlin, S. (1978) Biophys. J. 21, 35-70

35 Schwartz, A., Nagano, K., Nakao, M. Lindenmayer, G.E. and Allen, J.C. (1971) Methods Pharmacol. 1, 361-388

36 Marcus, M.M., Apell, H.-J., Roudna, M., Schwendener, R.A., Weder, H.-G. and Läuger, P. (1986) Biochim. Biophys. Acta 854, 270-278 